\title{
Limitations of median nerve somatosensory evoked potential monitoring during carotid endarterectomy
}

\author{
Sumito Okuyama, MD, ${ }^{1}$ Shinjitsu Nishimura, MD, ${ }^{1}$ Yoshiharu Takahashi, MD, ${ }^{1}$ Keiichi Kubota, MD, ${ }^{1}$ \\ Takayuki Hirano, MD, ${ }^{1}$ Ken Kazama, MD, ${ }^{1}$ Masato Tomii, MD, ${ }^{1}$ Junko Matsuyama, MD,1 \\ Junichi Mizuno, MD, ${ }^{1}$ Tadao Matsushima, MD, ${ }^{1}$ Masataka Sato, BS, ${ }^{2}$ and Kazuo Watanabe, MD ${ }^{1}$
}

Departments of ${ }^{1}$ Neurosurgery and ${ }^{2}$ Laboratory Medicine, Southern Tohoku General Hospital, Iwanuma, Japan

\begin{abstract}
OBJECTIVE Hypoperfusion during carotid artery cross-clamping (CC) for carotid endarterectomy (CEA) may result in the major complication of perioperative stroke. Median nerve somatosensory evoked potential (MNSSEP) monitoring, which is an established method for the prediction of cerebral ischemia, has low sensitivity in detecting such hypoperfusion. In this study the authors sought to explore the limitations of MNSSEP monitoring compared to tibial nerve somatosensory evoked potential (TNSSEP) monitoring for the detection of CC-related hypoperfusion.
\end{abstract}

METHODS The authors retrospectively analyzed data from patients who underwent unilateral CEA with routine shunt use. All patients underwent preoperative magnetic resonance angiography and were monitored for intraoperative cerebral ischemia by using MNSSEP, TNSSEP, and carotid stump pressure during CC. First, the frequency of MNSSEP and TNSSEP changes during CC were analyzed. Subsequently, variables related to stump pressure were determined by using linear analysis and those related to each of the somatosensory evoked potential (SSEP) changes were determined by using logistic regression analysis.

RESULTS A total of 94 patients (mean age 74 years) were included in the study. TNSSEP identified a greater number of SSEP changes during CC than MNSSEP $(20.2 \%$ vs $11.7 \% ; p<0.05)$. Linear regression analysis demonstrated that hypoplasia of the contralateral proximal segment of the anterior cerebral artery ( $A_{1}$ hypoplasia) $(p<0.01)$ and hypoplasia of the ipsilateral precommunicating segment of the posterior cerebral artery $\left(P_{1}\right.$ hypoplasia $)(p=0.02)$ independently and negatively correlated with stump pressure. Both contralateral $\mathrm{A}_{1}$ hypoplasia (OR 26.25, 95\% $\mathrm{Cl} 4.52-152.51$ ) and ipsilateral $\mathrm{P}_{1}$ hypoplasia $(\mathrm{OR} 8.75,95 \% \mathrm{Cl} 1.83-41.94)$ were independently related to the TNSSEP changes. However, only ipsilateral $\mathrm{P}_{1}$ hypoplasia (OR 8.76, 95\% Cl 1.61-47.67) was independently related to MNSSEP changes.

CONCLUSIONS TNSSEP monitoring appears to be superior to MNSSEP in detecting CC-related hypoperfusion. Correlation with stump pressure and SSEP changes indicates that TNSSEP, and not MNSSEP monitoring, is a reliable indicator of cerebral ischemia in the territory of the anterior cerebral artery.

https://thejns.org/doi/abs/10.3171/2018.4.JNS171784

KEYWORDS carotid endarterectomy; hypoperfusion; somatosensory evoked potential; circle of Willis; collateral circulation; diagnostic technique

O AROTID endarterectomy (CEA) is a promising procedure for symptomatic and asymptomatic patients with severe carotid artery stenosis. ${ }^{2,5,16,27,28} \mathrm{Me}$ dian nerve somatosensory evoked potential (MNSSEP) monitoring during CEA is useful in identifying intraoperative cerebral hypoperfusion, which is related to the risk of perioperative stroke and deficits in cognitive performance. . $, 8,19,22,24^{2}$
Reported studies have investigated the limitations of MNSSEP monitoring during CEA. MNSSEP is less sensitive than electroencephalography in detecting carotid artery cross-clamping (CC)-related ischemia, and furthermore, there are inconsistencies between MNSSEP and near-infrared spectroscopy changes. ${ }^{3,9,17}$ There are also case reports of perioperative cerebral infarctions in the absence of MNSSEP changes. ${ }^{6,11}$ A recent meta-analysis

ABBREVIATIONS ACA = anterior cerebral artery; $\mathrm{ACOA}=$ anterior communicating artery; $\mathrm{CC}=$ carotid artery cross-clamping; $\mathrm{CEA}=$ carotid endarterectomy; $\mathrm{MNSSEP}=$ median nerve somatosensory evoked potential; MRA = magnetic resonance angiography; $\mathrm{PCOA}=$ posterior communicating artery; SSEP = somatosensory evoked potential; TIA = transient ischemic attack; TNSSEP = tibial nerve somatosensory evoked potential.

SUBMITTED September 22, 2017. ACCEPTED April 2, 2018.

INCLUDE WHEN CITING Published online September 7, 2018; DOI: 10.3171/2018.4.JNS171784. 
described MNSSEP monitoring as having high specificity (91\%) but low sensitivity (58\%) in the prediction of perioperative stroke. ${ }^{18}$ However, the reasons for its lower sensitivity are yet to be explained.

MNSSEP is thought to be derived from the territory supplied by the middle cerebral artery and may not detect hypoperfusion in the territory of the anterior cerebral artery (ACA). On the other hand, tibial nerve somatosensory evoked potential (TNSSEP) monitoring may, owing to the territory involved, detect hypoperfusion in the ACA territory.$^{21}$ However, only a few studies have explored the role of TNSSEP monitoring during CEA. ${ }^{12,14}$

In this study, we evaluated hypoperfusion by measuring stump pressure ${ }^{23}$ and defined the factors that correlated with stump pressure reductions. Subsequently, we explored whether MNSSEP and TNSSEP could detect these hypoperfusion-related factors.

Our study involved three sequential steps. First, we explored the relationship between MNSSEP and TNSSEP changes during CC-related hypoperfusion. Second, we determined the factors associated with stump pressure reduction. Third, we analyzed the factors associated with MNSSEP and TNSSEP changes. We expected that these steps would explain the limitations of MNSSEP.

\section{Methods \\ Patients}

After institutional review board approval, we retrospectively reviewed the records of consecutive patients undergoing CEA for symptomatic or asymptomatic carotid stenosis at our institution from July 2011 to December 2015. The inclusion criteria were as follows: 1) Absence of significant carotid artery stenosis on the nonoperated side; 2) completion of preoperative magnetic resonance angiography (MRA); and 3) availability of assessable intraoperative data (MNSSEP, TNSSEP, and stump pressure). Data pertaining to preoperative demographic factors (age and sex), comorbidity (smoking, hypertension, hyperlipidemia, diabetes mellitus, symptomatic stroke, and transient ischemic attack), and perioperative factors (side of lesion and occlusion time [total time of shunt placement and removal]) were collected.

\section{Imaging Evaluation}

All patients underwent preoperative MRA performed with a 1.5-T MR imaging unit (Signa, GE Healthcare) with 3D time-of-flight pulse sequences. The absence of the anterior communicating artery $(\mathrm{ACoA})$, proximal segment of the anterior cerebral artery $\left(\mathrm{A}_{1}\right)$, posterior communicating artery (PCoA), and precommunicating segment of the posterior cerebral artery $\left(\mathrm{P}_{1}\right)$ were evaluated retrospectively by two authors (S.O. and Y.T.) who were blinded to the patients' clinical and perioperative information. The paired collateral vessels of the circle of Willis $\left(\mathrm{A}_{1}, \mathrm{PCoA}\right.$, and $\left.\mathrm{P}_{1}\right)$ were analyzed as ipsilateral and contralateral to the CEA side. The ACoA, which was located in the midline, was analyzed as a single collateral vessel. In the event of a lack of consensus between the two authors, the opinion of the senior author (S.N.) was considered as final. Cohen $\kappa$ was used to guarantee the interobserver concordance for MRA evaluation. There was a good agreement with $\mathrm{K}$ values of 0.78 for $\mathrm{ACoA}, 0.91$ for $\mathrm{A}_{1}, 0.86$ for PCoA, and 0.97 for $\mathrm{P}_{1}$.

\section{Carotid Endarterectomy and SSEP}

All CEA procedures were performed with the patient under general anesthesia and with MNSSEP and TNSSEP monitoring. A T-shaped flexible shunt tube (Mizuho Co., Ltd.) that was placed for all cases provided stump pressure measurements. During the carotid occlusion, if the amplitude of somatosensory evoked potential (SSEP; N20/ P25 for MNSSEP and P40/N50 for TNSSEP) decreased by more than $50 \%$, it was defined as an SSEP change. If SSEP changes were observed, we made efforts to declamp as fast as possible, and then we increased blood pressure and administered edaravone.

Real-time monitoring of SSEP was performed by using an intraoperative monitoring device (Nicolet Endeavor CR, Nicolet Biomedical, Inc.). Bilateral median and posterior tibial nerves were stimulated at the wrists and medial part of the ankles, respectively. Stimuli were repeated 100-200 times, every $300 \mathrm{msec}$, at amplitudes of 20-25 $\mathrm{mA}$ (350 $\mu \mathrm{sec}$ square pulse) for MNSSEP and $30 \mathrm{~mA}$ (350 $\mu$ sec square pulse) for TNSSEP. MNSSEP and TNSSEP were recorded from the lateral $\left(\mathrm{C}^{\prime} / \mathrm{C} 4^{\prime}-\mathrm{Fpz}\right)$ and medial (CPz-Fpz) parietal regions, respectively. Baseline waveforms were recorded following the induction of general anesthesia and before CC, while MNSSEP and TNSSEP were recorded during CC.

\section{Statistical Analysis}

The frequencies of MNSSEP and TNSSEP changes and their overlaps were determined to establish the relationship between the two methods of monitoring. Paired categorical data were analyzed with the binomial exact version of the McNemar test. Confidence intervals were estimated by using the nonparametric bootstrap method.

Univariate analysis was performed for demographic, radiographic, and perioperative factors and patient comorbidity by using a Student t-test to determine the contribution of these variables to stump pressure reduction. All variables with a univariate $p$ value $<0.2$ were included in stepwise multivariable linear models.

Factors related to the contribution of each SSEP change were identified by univariate and multivariable analysis. In univariate analysis, patients with and without SSEP changes were compared by using a Student t-test for continuous variables and a chi-square test for dichotomous variables. In the multivariable analysis, logistic regression was used while adjusting for the clinical factors. We adjusted for potential confounders by applying a stepwise method and included variables with a univariate $p$ value $<$ 0.2 in multivariable logistic models.

All statistical analyses were performed with SAS version 9.4 (SAS Institute Inc.) and Matlab (The Mathworks). In all cases, 2-sided tests were used, with a value of $\mathrm{p}<$ 0.05 considered statistically significant.

\section{Results}

\section{Patient Characteristics}

A total of 109 patients underwent CEA at our insti- 
TABLE 1. Clinical characteristics in 94 patients

\begin{tabular}{|c|c|}
\hline & Value \\
\hline \multicolumn{2}{|l|}{ Demographics } \\
\hline Age, yrs & $74 \pm 6$ \\
\hline Female & $13(14)$ \\
\hline \multicolumn{2}{|l|}{ Comorbidity } \\
\hline Hypertension & $69(73)$ \\
\hline Hyperlipidemia & $56(60)$ \\
\hline Diabetes mellitus & $38(40)$ \\
\hline Smoking & $29(35)$ \\
\hline Symptomatic lesion & $51(54)$ \\
\hline TIA & $18(19)$ \\
\hline \multicolumn{2}{|l|}{ MRA data* } \\
\hline ACoA, absent & $18(19)$ \\
\hline Ipsilat $A_{1}$, absent & $13(14)$ \\
\hline Contralat $A_{1}$, absent & $10(11)$ \\
\hline Ipsilat PCoA, absent & $81(86)$ \\
\hline Contralat PCoA, absent & $81(86)$ \\
\hline Ipsilat $P_{1}$, absent & $8(9)$ \\
\hline Contralat $\mathrm{P}_{1}$, absent & $9(10)$ \\
\hline \multicolumn{2}{|l|}{ Periop data } \\
\hline Rt side & $57(61)$ \\
\hline Occlusion time, secs & $992 \pm 234$ \\
\hline
\end{tabular}

Values are presented as the number of patients (\%) or mean \pm SD.

* Ipsilateral and contralateral correspond to the side of operations.

tution between July 2011 and December 2015. Of these, 15 patients were excluded for reasons that included bilateral operations (11 cases), unavailability of MNSSEP (1 case) and TNSSEP (1 case) recordings, and lack of stump pressure data when intraluminal shunts were not used (2 cases). Finally, 94 patients were included in the analysis (mean age $74 \pm 6$ years; women, $14 \%$; symptomatic, $54 \%$ ). Baseline characteristics of the patients are shown in Table 1. Postoperative neurological deficits were observed in 6 patients $(6 \%)$. Two patients developed transient ischemic attack (TIA) without postoperative stroke. Among the 4 cases in which patients developed postoperative stroke, 2 resolved completely within 3 months, and the remaining 2 had permanent disability.

\section{Distribution of MNSSEP and TNSSEP Changes}

Carotid cross-clamping was associated with SSEP changes in $22.3 \%$ of patients (21/94). TNSSEP monitoring detected more SSEP changes than MNSSEP monitoring $(20.2 \%$ vs $11.7 \%$, $\mathrm{p}<0.05$; Fig. 1$)$. The proportion of the study population that showed TNSSEP changes without MNSSEP changes (isolated TNSSEP changes) was $10.6 \%$ (10/94), and this proportion was significantly more frequent than zero (95\% CI 5.3-17.2). However, the proportion of patients with MNSSEP changes but without TNSSEP changes (isolated MNSSEP) $(2.1 \%, 2 / 94)$ was not significantly more frequent than zero $(95 \%$ CI 0-5.3). These findings statistically confirm the presence of isolated TNSSEP changes. Detailed characteristics of

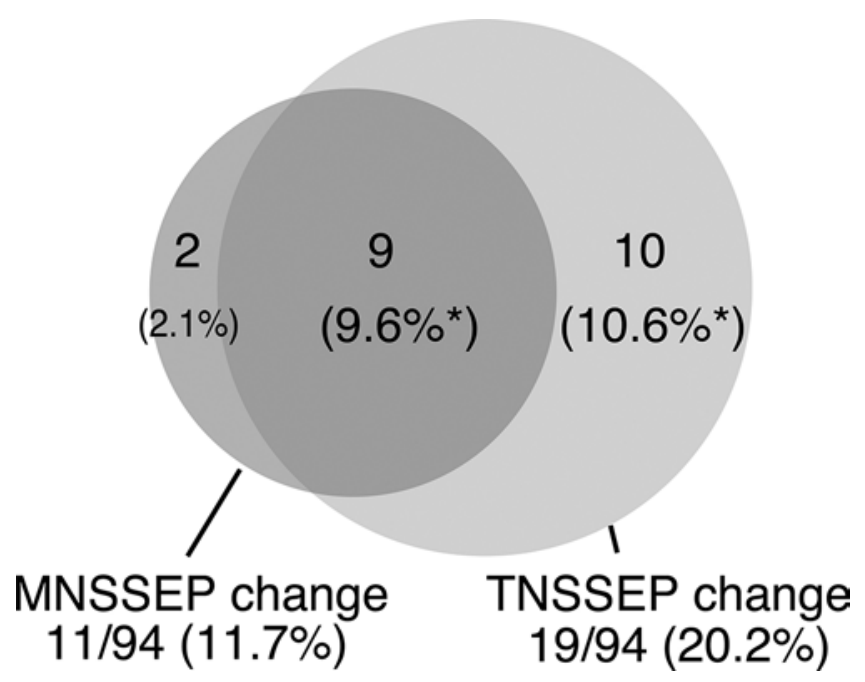

FIG. 1. Venn diagram illustrating the distributions of the patients who showed changes with either MNSSEP or TNSSEP monitoring or with both methods. *Significantly different from zero $(p<0.05)$.

patients who showed postoperative stroke symptoms or SSEP changes are shown in Table 2. In this study, we did not find an association between CC time and postoperative deficits (univariate regression, $\mathrm{p}=0.47$ ).

\section{Predictors of Stump Pressure Decline}

To determine the factors related to hypoperfusion, we analyzed the relationship between stump pressure decline and clinical variables. Hypertension, diabetes, absent contralateral $\mathrm{A}_{1}$, absent ipsilateral PCoA, and absent ipsilateral $P_{1}$ were found to be significant variables on univariate analysis. On multivariate analysis, only absent contralateral $\mathrm{A}_{1}(\beta[\mathrm{SE}]-21.44$ [7.16], $\mathrm{p}<0.01)$ and absent ipsilateral $\mathrm{P}_{1}(\beta[\mathrm{SE}]-16.17$ [7.02], $\mathrm{p}=0.02)$ were found to be independently associated with stump pressure decline (Table 3).

\section{Predictors of MNSSEP and TNSSEP Changes}

A logistic regression model was designed to identify whether MNSSEP and TNSSEP monitoring could detect the absence of contralateral $\mathrm{A}_{1}$ and ipsilateral $\mathrm{P}_{1}$, which were identified as predictive factors for hypoperfusion as measured by stump pressure. The model indicated that MNSSEP was significantly associated with absent ipsilateral $\mathrm{P}_{1}(\mathrm{OR} 6.77,95 \%$ CI 1.33-34.45, $\mathrm{p}=0.02)$ but not with absent contralateral $\mathrm{A}_{1}$ (OR 3.25, 95\% CI 0.56-18.86, $\mathrm{p}=$ 0.19). TNSSEP was significantly associated with both absent ipsilateral $\mathrm{P}_{1}$ (OR 5.14, 95\% CI 1.15-23.04, $\mathrm{p}=0.03$ ) and absent contralateral $A_{1}$ (OR 18.50, 95\% CI 3.34-102.55, $\mathrm{p}<0.001)$. After adjustment for potential confounders, the association between MNSSEP changes and CC was significant in cases with absent ipsilateral $\mathrm{P}_{1}(\mathrm{OR} 8.76,95 \%$ CI 1.61-47.67, $\mathrm{p}=0.01)$, but not with absent contralateral $\mathrm{A}_{1}$ (OR 4.87, 95\% CI 0.77-30.61, $\mathrm{p}=0.09$ ). The association between TNSSEP changes and $\mathrm{CC}$ was significant both in cases with absent ipsilateral $\mathrm{P}_{1}(\mathrm{OR} 8.75,95 \% \mathrm{CI}$ $1.83-41.94, \mathrm{p}<0.01)$ and in cases with absent contralateral $\mathrm{A}_{1}$ (OR 26.25, 95\% CI 4.52-152.51, p < 0.001) (Fig. 2). 
TABLE 2. Clinical features of patients with postoperative symptoms or SSEP changes

\begin{tabular}{|c|c|c|c|c|c|c|c|}
\hline $\begin{array}{l}\text { Age (yrs), } \\
\text { Sex }\end{array}$ & $\begin{array}{l}\text { Op } \\
\text { Side }\end{array}$ & $\begin{array}{l}\text { MNSSEP } \\
\text { Change* }^{*}\end{array}$ & $\begin{array}{l}\text { TNSSEP } \\
\text { Change }^{*}\end{array}$ & $\begin{array}{c}\text { Absence } \\
\text { of } A_{1} \dagger\end{array}$ & $\begin{array}{c}\text { Absence } \\
\text { of } P_{1} \dagger\end{array}$ & $\begin{array}{l}\text { Occlusion } \\
\text { Time (secs) }\end{array}$ & Symptomatic Stroke \\
\hline $80, M$ & Lt & No & Bilat & Contralat & Contralat & 1039 & TIA \\
\hline $65, \mathrm{M}$ & Rt & No & Bilat & Ipsilat & No & 954 & Transient It hemiparesis; rt watershed infarctions \\
\hline $78, \mathrm{M}$ & Rt & $\mathrm{Lt}$ & $\mathrm{Lt}$ & No & No & 914 & Transient It hemiparesis; rt watershed infarctions \\
\hline $78, \mathrm{M}$ & Rt & No & Rt & No & Ipsilat & 1085 & TIA \\
\hline $69, \mathrm{M}$ & $\mathrm{Lt}$ & Rt & Rt & No & Bilat & 719 & Rt hemiparesis; It MCA territory infarctions \\
\hline $81, \mathrm{M}$ & $\mathrm{Lt}$ & No & No & No & No & 1635 & Rt hemiparesis; It watershed infarctions \\
\hline $71, \mathrm{M}$ & $\mathrm{Lt}$ & No & Bilat & Contralat & No & 930 & No \\
\hline $83, \mathrm{M}$ & Rt & $\mathrm{Lt}$ & $\mathrm{Lt}$ & No & No & 1110 & No \\
\hline $80, \mathrm{M}$ & $\mathrm{Lt}$ & No & Rt & No & No & 1149 & No \\
\hline $72, \mathrm{~F}$ & $\mathrm{Rt}$ & Lt & $\mathrm{Lt}$ & Ipsilat & Ipsilat & 1563 & No \\
\hline $74, \mathrm{M}$ & Rt & $\mathrm{Lt}$ & No & No & No & 693 & No \\
\hline $72, \mathrm{M}$ & $\mathrm{Lt}$ & Rt & Rt & Contralat & No & 1053 & No \\
\hline $79, \mathrm{~F}$ & $\mathrm{Lt}$ & No & Bilat & Contralat & No & 755 & No \\
\hline $75, \mathrm{M}$ & $\mathrm{Lt}$ & Rt & No & Contralat & No & 879 & No \\
\hline $74, \mathrm{M}$ & Rt & No & Bilat & No & No & 1232 & No \\
\hline $67, \mathrm{M}$ & Rt & $\mathrm{Lt}$ & $\mathrm{Lt}$ & No & No & 973 & No \\
\hline $77, \mathrm{M}$ & Rt & $\mathrm{Lt}$ & Bilat & No & No & 1373 & No \\
\hline $69, \mathrm{M}$ & Rt & No & Rt & Contralat & No & 980 & No \\
\hline $78, \mathrm{M}$ & Rt & $\mathrm{Lt}$ & $\mathrm{Lt}$ & Ipsilat & Ipsilat & 730 & No \\
\hline $78, \mathrm{M}$ & Rt & No & $\mathrm{Lt}$ & Contralat & No & 1044 & No \\
\hline $78, \mathrm{M}$ & Rt & $\mathrm{Lt}$ & $\mathrm{Lt}$ & No & No & 902 & No \\
\hline $70, M$ & Rt & No & $\mathrm{Rt}$ & No & No & 936 & No \\
\hline
\end{tabular}

* SSEP changes observed by stimulating the right or left extremity. $\dagger$ Ipsilateral and contralateral correspond to the side of operations.

TABLE 3. Correlation between stump pressure and clinical variables: univariate analysis

\begin{tabular}{lc}
\hline \multicolumn{1}{c}{ Variable } & Stump Pressure Correlation, $\mathrm{mm} \mathrm{Hg}(\mathrm{SE})$ \\
\hline Age & $-0.38(0.33)$ \\
\hline Female & $0.48(6.03)$ \\
\hline Hypertension & $-7.03(4.65)$ \\
\hline Hyperlipidemia & $-0.50(4.24)$ \\
\hline Diabetes & $5.58(4.20)$ \\
\hline Smoking & $4.16(4.48)$ \\
\hline Symptomatic lesion & $-1.90(4.17)$ \\
\hline TIA & $0.35(5.29)$ \\
\hline Rt side & $-1.20(4.26)$ \\
\hline ACoA, absent & $2.26(4.99)$ \\
\hline Ipsilat $\mathrm{A}_{1}$, absent & $-3.99(6.01)$ \\
\hline Contralat $\mathrm{A}_{1}$, absent & $-16.87(7.25)^{\star}$ \\
\hline Ipsilat $\mathrm{PCo}_{\mathrm{A}}$, absent & $-7.15(5.35)$ \\
\hline Contralat $\mathrm{PCoA}$, absent & $-3.53(5.67)$ \\
\hline Ipsilat $\mathrm{P}_{1}$, absent & $-15.10(7.29)^{*}$ \\
\hline Contralat $\mathrm{P}_{1}$, absent & $-7.36(7.03)$ \\
\hline Occlusion time & $0.002(0.01)$ \\
\hline
\end{tabular}

${ }^{*} p<0.05$.

\section{Association With Perioperative Symptoms}

Univariate logistic regression identified that TNSSEP change was significantly related to perioperative stroke or symptoms (OR 27.14, 95\% CI 2.94-250.27, $\mathrm{p}<0.01$ ), but MNSSEP change was not (OR 4.50, 95\% CI 0.72-28.10, $\mathrm{p}=0.11)$.

\section{Discussion}

In our study, we compared and analyzed the differences in the changes between TNSSEP and MNSSEP monitoring for the detection of CC-related hypoperfusion during CEA for carotid artery stenosis. We found that cerebral hypoperfusion was more frequently detected by TNSSEP than by MNSSEP monitoring. Contralateral $\mathrm{A}_{1}$ hypoplasia and ipsilateral $P_{1}$ hypoplasia were found to be significant factors that predicted cerebral hypoperfusion as measured by stump pressure. The changes in TNSSEP reflected both of these predictive factors while the changes in MNSSEP reflected only ipsilateral $\mathrm{P}_{1}$ hypoplasia, suggesting that MNSSEP monitoring may not detect hypoperfusion in the ACA territory. Therefore, this study supports the wellknown fact that MNSSEP monitoring identifies hypoperfusion in the MCA but not the ACA territory. ${ }^{12,15}$

Previous studies have demonstrated that MNSSEP monitoring during CEA has high specificity but low sensitivity for the prediction of perioperative stroke. However, 


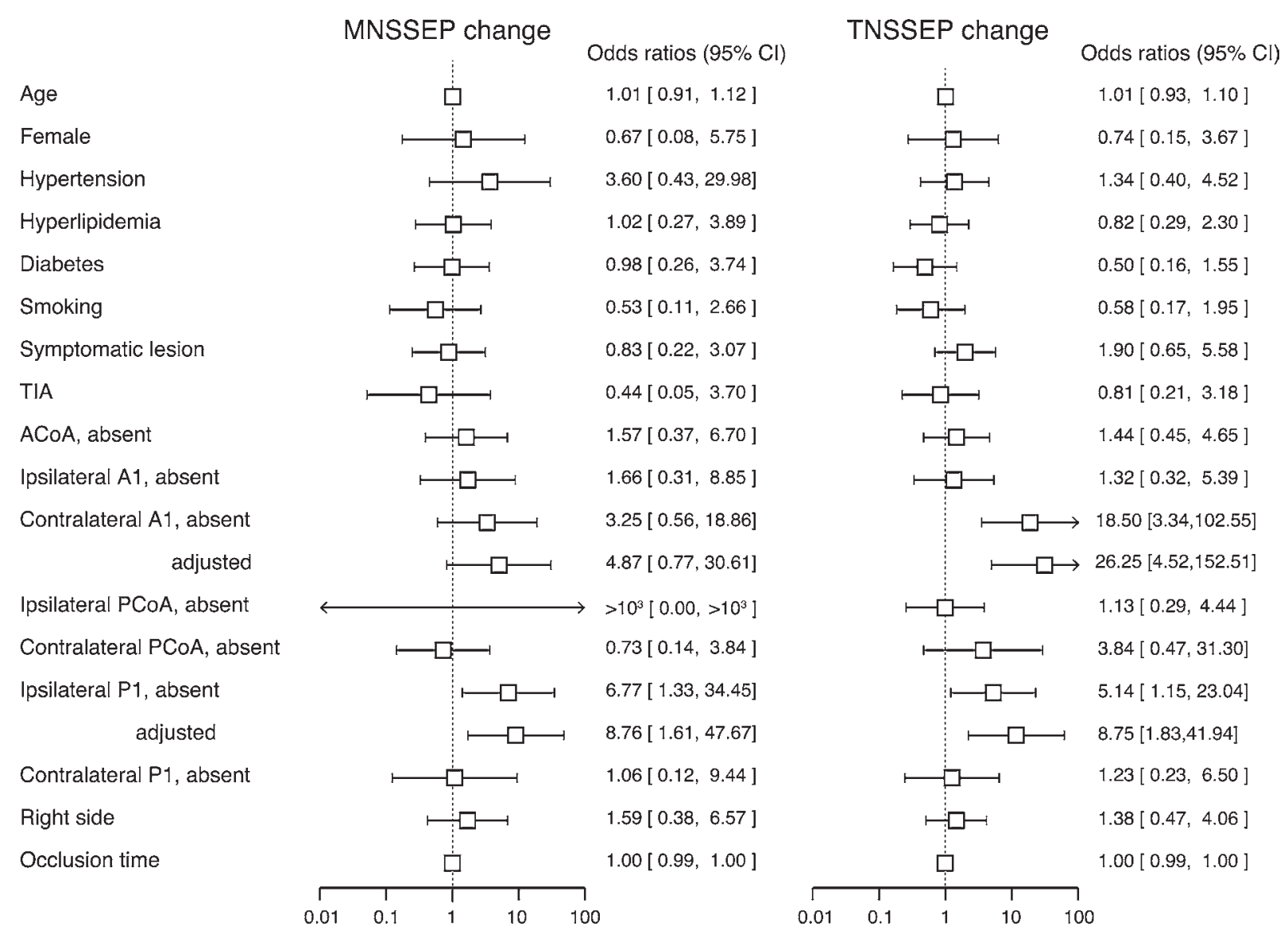

FIG. 2. Forest plot demonstrating the association of SSEP changes and clinical variables.

the reasons for this lower sensitivity of MNSSEP have not been explained. The main component of MNSSEP, N20, reflects the sensation of the arm corresponding to the lateral part of the primary sensory cortex and is located in the posterior part of the inverted omega convexity in the central sulcus. ${ }^{1}$ On the other hand, P40 of TNSSEP reflects the sensation of the ankle corresponding to the medial surface of the primary motor cortex. ${ }^{26}$ Despite the neurophysiological evidence that CC-related hypoperfusion affects both the lateral and medial parts of the cerebral cortex, most centers use MNSSEP alone for monitoring cerebral hypoperfusion during CEA.

We determined absent contralateral $A_{1}$ as one of the predictors of cerebral hypoperfusion as measured by stump pressure. However, according to our data, this does not affect MNSSEP, suggesting that changes in MNSSEP are not associated with ACA-related collateral function. This implies that MNSSEP monitoring may not detect hypoperfusion in the ACA territory during $\mathrm{CC}$, explaining the $10.6 \%$ rate of isolated TNSSEP changes in our study.

In the present study, we explored SSEP changes caused by $\mathrm{CC}$ and correlated them with the incidence of major complications. On analyzing data from 6 patients who developed perioperative stroke or symptoms, significant SSEP changes were observed in 2 cases during MNSSEP monitoring and in 5 cases during TNSSEP monitoring.
In 3 cases isolated TNSSEP changes occurred without MNSSEP changes; in 2 of these cases the $\mathrm{A}_{1}$ segment was absent. These findings further reinforce the conclusion that MNSSEP monitoring may fail to detect ACA-related hypoperfusion. The association of TNSSEP with perioperative stroke and lack of association between MNSSEP and stroke further suggest the superiority of TNSSEP.

We used intraluminal shunts in all cases, but short-term $\mathrm{CC}$ during shunt insertion can cause cerebral hypoperfusion, depending on variations in collateral circulation. Weigand et al. ${ }^{29}$ reported that $6 \pm 1$ minutes of occlusion during shunt insertion caused jugular venous-arterial malondialdehyde concentration differences. Inoue et al. ${ }^{8}$ demonstrated that MNSSEP changes caused by $17 \pm 5$ minutes of $\mathrm{CC}$ for shunt insertion were associated with lower postoperative cognitive functions. We found no association between CC time and postoperative deficit; however, to reduce subclinical complications, we detected cerebral ischemia using MNSSEP and TNSSEP monitoring. SSEP changes were addressed by declamping as fast as possible, increasing blood pressure, and administering edaravone. MNSSEP and TNSSEP would be valuable for detection of a short term of hypoperfusion and their alarms should be attended to, to increase the safety of carotid endarterectomy.

Our study found isolated TNSSEP changes in $10.6 \%$ of 
patients (10/94), demonstrating the superiority of monitoring with TNSSEP over MNSSEP in the detection of CCrelated hypoperfusion. However, Manninen et al..$^{14}$ found no isolated TNSSEP changes (0/153), while Malcharek et al. ${ }^{12}$ found isolated TNSSEP changes in 1.1\% (3/264) of their patients. This discrepancy may be explained by differences in the stimulus techniques employed by different investigators. Good-quality SSEPs require a stimulus high enough to obtain supramaximal SSEP amplitude.? We used $350 \mu \mathrm{sec}$ of square pulse, compared to the impulse duration in their study of $250 \mu \mathrm{sec}$, a value greater by 1.4 times. In addition, Malcharek et al. also reported a higher failure rate with TNSSEP monitoring $(7.9 \%-12 \%)$ than ours $(1 \% ; 1 / 96)$, suggesting significant procedural differences between our studies.

Recently, multimodal monitoring during CEA has more commonly involved TNSSEP recording than previously; this method helps to prevent ischemic complications or to inform the selection of intraluminal shunts. It is worth mentioning that there is a difference in laterality of SSEP change between MNSSEP and TNSSEP. In our patients there were 19 cases of TNSSEP changes, for which changes in the ipsilateral lower extremity were observed in 9 cases $(47 \% ; 9 / 19)$. On the other hand, no MNSSEP changes were observed in the ipsilateral upper extremity $(0 \% ; 0 / 11)$. Thus, SSEP changes of the ipsilateral extremity were more common in TNSSEP monitoring. We believe these ipsilateral TNSSEP changes should not be regarded as false positives but should be used to inform clinical decision-making.

We detected two types of abnormal collaterals of the circle of Willis that were predictive of a higher risk of CCrelated hypoperfusion. Both of these variants result in a greater perfusion demand on the internal carotid artery (ICA). Tanaka et al. analyzed volume flow rates of the ICA and basilar artery in healthy volunteers and found an increase in the relative flow rates of the contralateral ICA (by 25\%) and the ipsilateral ICA (by 18\%) in subjects with $\mathrm{A}_{1}$ and $\mathrm{P}_{1}$ hypoplasia compared to flow rates in subjects with normal cerebral vasculature. ${ }^{25}$ Similarly, increased flow in the ICA, as seen on MRA, is related to ischemic change during $\mathrm{CC}$, supporting the view that lesions resulting in such an increased flow may be reliable predictors of CC-related hypoperfusion. ${ }^{20}$

The present study has several limitations. First, this was a retrospective study and subject to the inherent limitations of such a study design. Second, the actual number of SSEP changes in our study was small, thus affecting the generalizability of our findings. Third, evaluating collateral function of the circle of Willis by using MRA has its own limitations. Reduced inflow in the anterior segment of the circle of Willis caused by carotid artery stenosis may affect the evaluation of the patency of the ACoA and ipsilateral $\mathrm{A}_{1}$. High-resolution MRA may overcome such a limitation. Fourth, in the current study, we did not employ electroencephalography, which covers a broader range of the cortex. Further research is warranted to compare the effectiveness of electroencephalography and TNSSEP. Finally, there is another limitation of MNSSEP and TNSSEP monitoring. MNSSEP and TNSSEP reflect the function of the thalamocortical pathway that projects to the primary somatosensory cortex and the primary motor cortex but do not reflect the corticospinal tract that is supplied by the lenticulostriate artery. ${ }^{10}$ To monitor the corticospinal tract, motor evoked potential (MEP) monitoring is a more reliable modality. ${ }^{13}$

\section{Conclusions}

Our study demonstrated that ACA-related hypoperfusion was associated with TNSSEP changes but not with MNSSEP changes during CEA. Routine use of MNSSEP monitoring with TNSSEP monitoring may reduce cerebral hypoperfusion and its attendant complications during CEA.

\section{References}

1. Balzamo E, Marquis P, Chauvel P, Régis J: Short-latency components of evoked potentials to median nerve stimulation recorded by intracerebral electrodes in the human pre- and postcentral areas. Clin Neurophysiol 115:1616-1623, 2004

2. Barnett HJM, Taylor DW, Haynes RB, Sackett DL, Peerless SJ, Ferguson GG, et al: Beneficial effect of carotid endarterectomy in symptomatic patients with high-grade carotid stenosis. N Engl J Med 325:445-453, 1991

3. Beese U, Langer H, Lang W, Dinkel M: Comparison of nearinfrared spectroscopy and somatosensory evoked potentials for the detection of cerebral ischemia during carotid endarterectomy. Stroke 29:2032-2037, 1998

4. Dinkel M, Schweiger H, Goerlitz P: Monitoring during carotid surgery: somatosensory evoked potentials vs. carotid stump pressure. J Neurosurg Anesthesiol 4:167-175, 1992

5. Halliday A, Mansfield A, Marro J, Peto C, Peto R, Potter $\mathrm{J}$, et al: Prevention of disabling and fatal strokes by successful carotid endarterectomy in patients without recent neurological symptoms: randomised controlled trial. Lancet 363:1491-1502, 2004

6. Haupt WF, Erasmi-Körber H, Lanfermann H: Intraoperative recording of parietal SEP can miss hemodynamic infarction during carotid endarterectomy: a case study. Electroencephalogr Clin Neurophysiol 92:86-88, 1994

7. Houlden DA, Ubriaco G, Stewart CP, Robertson SL, Cohen M, Potapova E, et al: Optimal intraoperative somatosensory evoked potential stimulus intensity can be determined by nerve action potential amplitude. J Clin Neurophysiol 29:509-513, 2012

8. Inoue T, Ohwaki K, Tamura A, Tsutsumi K, Saito I, Saito $\mathrm{N}$ : Subclinical ischemia verified by somatosensory evoked potential amplitude reduction during carotid endarterectomy: negative effects on cognitive performance. J Neurosurg 118:1023-1029, 2013

9. Kearse LA Jr, Brown EN, McPeck K: Somatosensory evoked potentials sensitivity relative to electroencephalography for cerebral ischemia during carotid endarterectomy. Stroke 23:498-505, 1992

10. Krieger D, Adams HP, Albert F, von Haken M, Hacke W: Pure motor hemiparesis with stable somatosensory evoked potential monitoring during aneurysm surgery: case report. Neurosurgery 31:145-150, 1992

11. Linstedt U, Maier C, Petry A: Intraoperative monitoring with somatosensory evoked potentials in carotid artery surgery-less reliable in patients with preoperative neurologic deficiency? Acta Anaesthesiol Scand 42:13-16, 1998

12. Malcharek MJ, Kulpok A, Deletis V, Ulkatan S, Sablotzki A, Hennig G, et al: Intraoperative multimodal evoked potential monitoring during carotid endarterectomy: a retrospective study of 264 patients. Anesth Analg 120:1352-1360, 2015

13. Malcharek MJ, Ulkatan S, Marinò V, Geyer M, Lladó-Carbó 
E, Perez-Fajardo G, et al: Intraoperative monitoring of carotid endarterectomy by transcranial motor evoked potential: a multicenter study of 600 patients. Clin Neurophysiol 124:1025-1030, 2013

14. Manninen P, Sarjeant R, Joshi M: Posterior tibial nerve and median nerve somatosensory evoked potential monitoring during carotid endarterectomy. Can J Anaesth 51:937-941, 2004

15. Manninen PH, Tan TK, Sarjeant RM: Somatosensory evoked potential monitoring during carotid endarterectomy in patients with a stroke. Anesth Analg 93:39-44, 2001

16. Mayberg MR, Wilson SE, Yatsu F, Weiss DG, Messina L, Hershey LA, et al: Carotid endarterectomy and prevention of cerebral ischemia in symptomatic carotid stenosis. Veterans Affairs Cooperative Studies Program 309 Trialist Group. JAMA 266:3289-3294, 1991

17. Nemoto EM: No absolutes in neuromonitoring for carotid endarterectomy. Stroke 30:895-897, 1999

18. Nwachuku EL, Balzer JR, Yabes JG, Habeych ME, Crammond DJ, Thirumala PD: Diagnostic value of somatosensory evoked potential changes during carotid endarterectomy: a systematic review and meta-analysis. JAMA Neurol 72:7380,2015

19. Prokop A, Meyer GP, Walter M, Erasmi H: Validity of SEP monitoring in carotid surgery. Review and own results. $\mathbf{J}$ Cardiovasc Surg (Torino) 37:337-342, 1996

20. Rutgers DR, Blankensteijn JD, van der Grond J: Preoperative MRA flow quantification in CEA patients: flow differences between patients who develop cerebral ischemia and patients who do not develop cerebral ischemia during cross-clamping of the carotid artery. Stroke 31:3021-3028, 2000

21. Sako K, Nakai H, Kawata Y, Takizawa K, Satho M, Yonemasu Y: Temporary arterial occlusion during anterior communicating or anterior cerebral artery aneurysm operation under tibial nerve somatosensory evoked potential monitoring. Surg Neurol 49:316-323, 1998

22. Schwartz ML, Panetta TF, Kaplan BJ, Legatt AD, Suggs WD, Wengerter KR, et al: Somatosensory evoked potential monitoring during carotid surgery. Cardiovasc Surg 4:77-80, 1996

23. Spencer MP, Thomas GI, Moehring MA: Relation between middle cerebral artery blood flow velocity and stump pressure during carotid endarterectomy. Stroke 23:1439-1445, 1992

24. Sussman ES, Kellner CP, Mergeche JL, Bruce SS, McDowell MM, Heyer EJ, et al: Radiographic absence of the posterior communicating arteries and the prediction of cognitive dysfunction after carotid endarterectomy. J Neurosurg 121:593-598, 2014
25. Tanaka H, Fujita N, Enoki T, Matsumoto K, Watanabe Y, Murase K, et al: Relationship between variations in the circle of Willis and flow rates in internal carotid and basilar arteries determined by means of magnetic resonance imaging with semiautomated lumen segmentation: reference data from 125 healthy volunteers. AJNR Am J Neuroradiol 27:1770-1775, 2006

26. Terada K, Umeoka S, Baba K, Sakura Y, Usui N, Matsuda K, et al: Generators of tibial nerve somatosensory evoked potential: recorded from the mesial surface of the human brain using subdural electrodes. J Clin Neurophysiol 26:13-16, 2009

27. Walker MD, Marler JR, Goldstein M, Grady PA, Toole JF, Baker WH, et al: Endarterectomy for asymptomatic carotid artery stenosis. JAMA 273:1421-1428, 1995

28. Warlow C: MRC European Carotid Surgery Trial: interim results for symptomatic patients with severe (70-99\%) or with mild (0-29\%) carotid stenosis. Lancet 337:1235-1243, 1991

29. Weigand MA, Laipple A, Plaschke K, Eckstein HH, Martin $\mathrm{E}$, Bardenheuer HJ: Concentration changes of malondialdehyde across the cerebral vascular bed and shedding of Lselectin during carotid endarterectomy. Stroke 30:306-311, 1999

\section{Disclosures}

The authors report no conflict of interest concerning the materials or methods used in this study or the findings specified in this paper.

\section{Author Contributions}

Conception and design: Okuyama, Nishimura. Acquisition of data: Okuyama, Nishimura, Takahashi, Kubota, Hirano, Kazama, Tomii, Matsuyama, Sato. Analysis and interpretation of data: Okuyama, Nishimura. Drafting the article: Okuyama. Critically revising the article: Nishimura. Reviewed submitted version of manuscript: Nishimura. Approved the final version of the manuscript on behalf of all authors: Okuyama. Statistical analysis: Okuyama, Takahashi. Administrative/technical/material support: Mizuno, Matsushima, Watanabe. Study supervision: Nishimura.

\section{Correspondence}

Sumito Okuyama: Southern Tohoku General Hospital, Iwanuma, Japan.okuyama.sumito@gmail.com. 